\title{
Research and Development of the Wind Turbine Reliability
}

\author{
Yao Li, Caichao Zhu*, Chaosheng Song, Jianjun Tan \\ The State of Key Laboratory of Mechanical Transmissions, Chongqing University, Chongqing, China \\ Email address: \\ yao_li_@outlook.com(YaoLi),cczhu@cqu.edu.cn (Caichao Zhu)
}

\section{To cite this article:}

Yao Li, Caichao Zhu, Chaosheng Song, Jianjun Tan. Research and Development of the Wind Turbine Reliability. International Journal of Mechanical Engineering and Applications. Vol. 6, No. 2, 2018, pp. 35-45. doi: 10.11648/j.ijmea.20180602.14

Received: March 19, 2018; Accepted: April 3, 2018; Published: May 18, 2018

\begin{abstract}
With the rapid development of wind power industry, the wind turbine reliability has become a hotspot in wind power research. The failure modes and research progress of wind turbine reliability both at home and abroad were analyzed. The failure modes, failure causes and detection methods of some key components in the wind turbines were summarized. Also, the frequently used methods of reliability analysis and research status of wind turbine reliability were analyzed. Following this, research focuses, methods and measures to improve wind turbine reliability were presented. We also shed light on the condition monitoring and assessment process with condition monitoring system and supervisory control and data acquisition. It is of great significance to reduce the cost of operation and maintenance and to improve the safety of wind turbines.
\end{abstract}

Keywords: Wind Turbines, Failure Modes, Reliability Analysis, Condition Monitoring, Assessment

\section{Introduction}

Fossil fuels are non-renewable and their associated prices are fluctuating sharply. Meanwhile, the increasing environmental and climatic concerns of the current times have moved the research focus from conventional electricity resources to renewable resources. Renewable energy resources, such as wind, solar, and geothermal power, are clean alternatives to fossil fuels. Among them, wind energy is one of the most promising renewable energy resources in the world today. The main attractions of wind energy are a large resource and low environmental impact. In this condition, wind energy is developing rapidly. For example, over 51.2 gigawatts $(\mathrm{GW})$ of capacity was installed in 2017 [1].

In recent years, wind power industry has been flourishing all over the world and in some countries the focus has been gradually shifted from land-based to offshore wind farms. On a global basis, the size of the annual market grew $42 \%$ year-over-year in 2014, compared to a 20 percent fall in 2013. By the end of 2017, the cumulative installed capacity climbed to $539 \mathrm{GW}[2,3]$, which is shown in Figure 3. Policy-driven accelerations play a very important role in market growth, especially in China, Germany, and the United States. In these three countries, China is the world's largest wind power market with $18 \mathrm{GW}$ of newly installed wind power in 2017. The development of wind power in China is shown in Figure 2. Figure 1 shows the top ten countries of newly installed capacity from January to December in 2016 [3]. The total installed capacity is up to 51473 megawatts (MW) and the share of China is up to $45.1 \%$. With more and more wind turbines being installed, lots of potential problems still need to be solved, such as fatigue, failures, condition monitoring, operation and maintenance, which are especially true in the current circumstances where the tower height, rotor diameter and overall turbine weight have almost quadrupled in size and capacity [4]. Hence, the reliability of wind turbines is becoming more important now than ever before. 


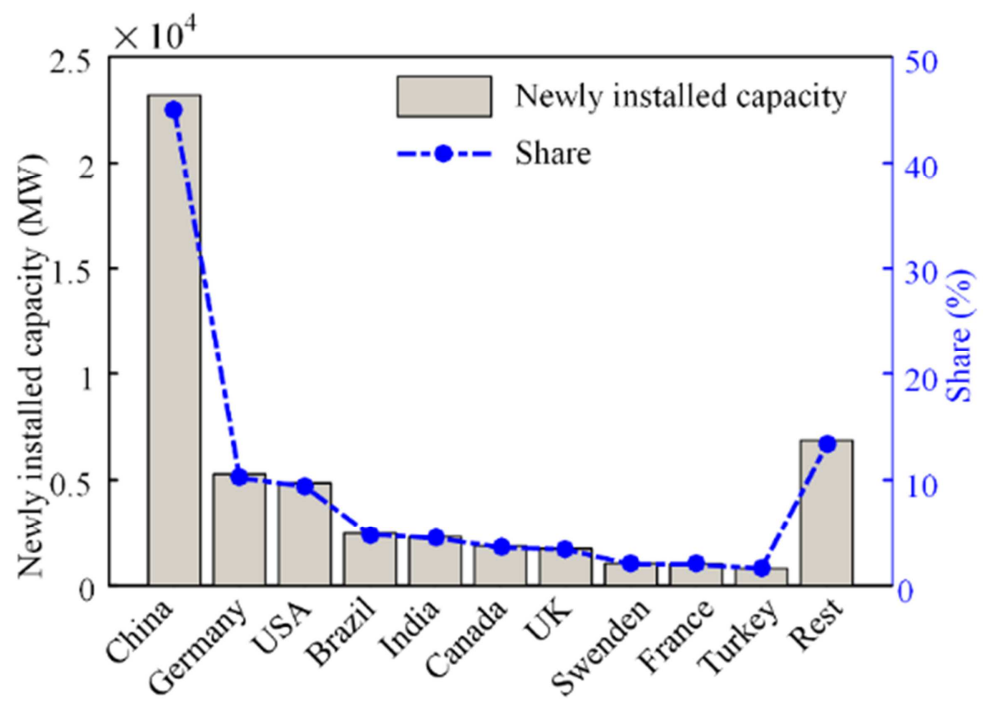

Figure 1. Top ten new installed capacity in 2016.

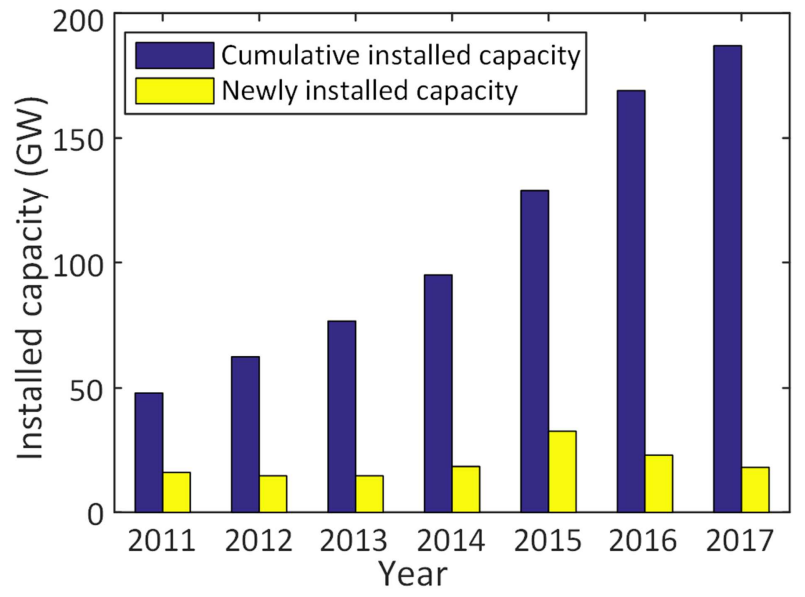

Figure 2. Wind power development in China.

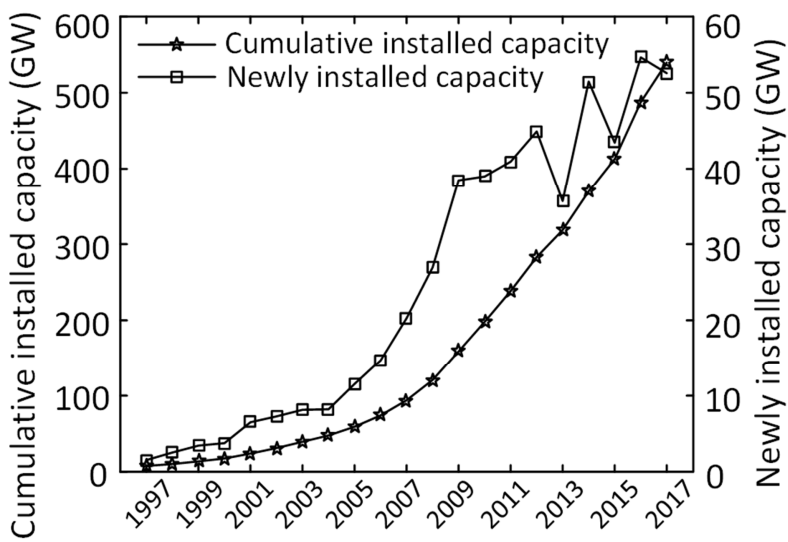

Figure 3. The global wind power capacity.

\section{Developments and Challenges}

In the late $1970 \mathrm{~s}$, in response to the oil price increasing around that time, a number of government programs were initiated with the objective of developing suitable wind turbines. To reduce the dependence on conventional electricity sources, the related countries carried out many programs and focused on the development of wind turbines, rating up to 4 MW and diameters up to $100 \mathrm{~m}$. Some examples are included in Table 1. Furthermore, the wind energy has witnessed rapid development in just decades, making it one of the fastest growing sources of electricity in the world today. But it is thought that wind energy is still immature these days. Due to technological advancements, policy initiatives, and economic drivers, wind energy is now able to make a cost-competitive contribution to our growing energy needs. For example, over 240,000 commercial-sized wind turbines were operating in the world by 2014 , producing $4 \%$ of the world's electricity $[5,6]$. Wind power showed the potential for replacing natural gas in electricity generation on the cost basis. Technological innovations continue to drive new developments in the application of wind power. Until now, the cumulative installed capacity has been more than $400 \mathrm{GW}$.

With the growing number of the wind turbines, the industry still need to face numerous challenges. A number of wind turbine components are prone to failure, and it is difficult and expensive to repair or replace them. For example, bearings, inverters and gearboxes, raise the maintenance issues. Still, wind energy challenges still exist due to: (1) Poor performance and reliability and (2) rising costs driven by transportation, maintenance, and so on. To achieve a longer life of wind turbines and to reduce the cost of maintenance, the development of technologies for improving the reliability of wind turbines is an important consideration for future development, especially for offshore wind turbines. Hence, measures must be taken to improve the reliability of wind turbines. 
Table 1. Some of the early prototype machines, mostly funded by governments.

\begin{tabular}{|c|c|c|c|c|c|c|}
\hline Location & Name & Rating & Diameter & Blades & Date & Features \\
\hline Canada & Eole & $3.6 \mathrm{MW}$ & $64 \mathrm{~m}$ & 2 & 1987 & Vertical axis, direct drive \\
\hline Denmark & Tjaereborg & $2 \mathrm{MW}$ & $61 \mathrm{~m}$ & 3 & 1988 & \\
\hline Germany & Growian & $3 \mathrm{MW}$ & $100 \mathrm{~m}$ & 2 & 1981 & \\
\hline Germany & Monopteros & $0.64 \mathrm{MW}$ & $50 \mathrm{~m}$ & 1 & 1989 & \\
\hline Italy & Gamma 60 & $1.5 \mathrm{MW}$ & $60 \mathrm{~m}$ & 2 & 1991 & Variable speed, Power control by yaw \\
\hline Netherlands & Newecs 45 & $1 \mathrm{MW}$ & $45 \mathrm{~m}$ & 2 & 1985 & \\
\hline Spain & AWEC-60 & 1.2 MW & $60 \mathrm{~m}$ & 3 & 1989 & Variable speed \\
\hline UK & LS1 & $3 \mathrm{MW}$ & $60 \mathrm{~m}$ & 2 & 1987 & Partial span pitch control \\
\hline USA & WTS-4 & $4 \mathrm{MW}$ & $78 \mathrm{~m}$ & 2 & 1982 & Similar to WTS3 (Sweden) \\
\hline USA & MOD-5B & $3.2 \mathrm{MW}$ & $99 \mathrm{~m}$ & 2 & 1987 & Variable speed \\
\hline
\end{tabular}

\section{Wind Turbine Failure Modes}

Nowadays, the development of wind turbines tends towards larger and heavier structures, which increases the failure frequency. In engineering reality, the failure rates are also very different between onshore and offshore wind turbine systems for the same type. Figure 4 shows components failure rates of wind turbine systems and components [7]. The results of Figure 4 show that some key components have high failure rates than that of other components, and the same components working offshore have much higher failure rates than those working onshore.

For a wind turbine transmission system, key components like the generator, gearbox, and blades have the highest failure rates. The gearbox failures are mainly caused by gears and bearings; the generator failures are mainly caused by bearings. Table 2 shows the failure modes, failure causes and detection methods of wind turbine key components and sub-assemblies.

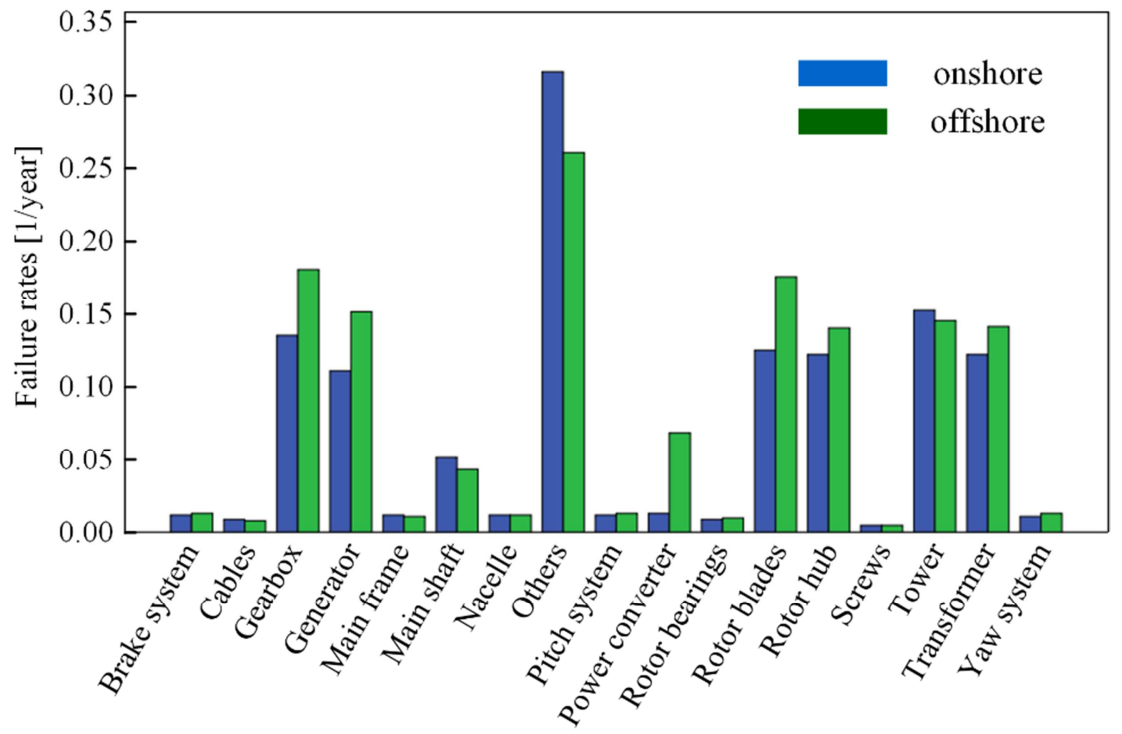

Figure 4. Failure rates for wind turbine sub-assemblies working in onshore and offshore.

Table 2. Summary on failure modes of components.

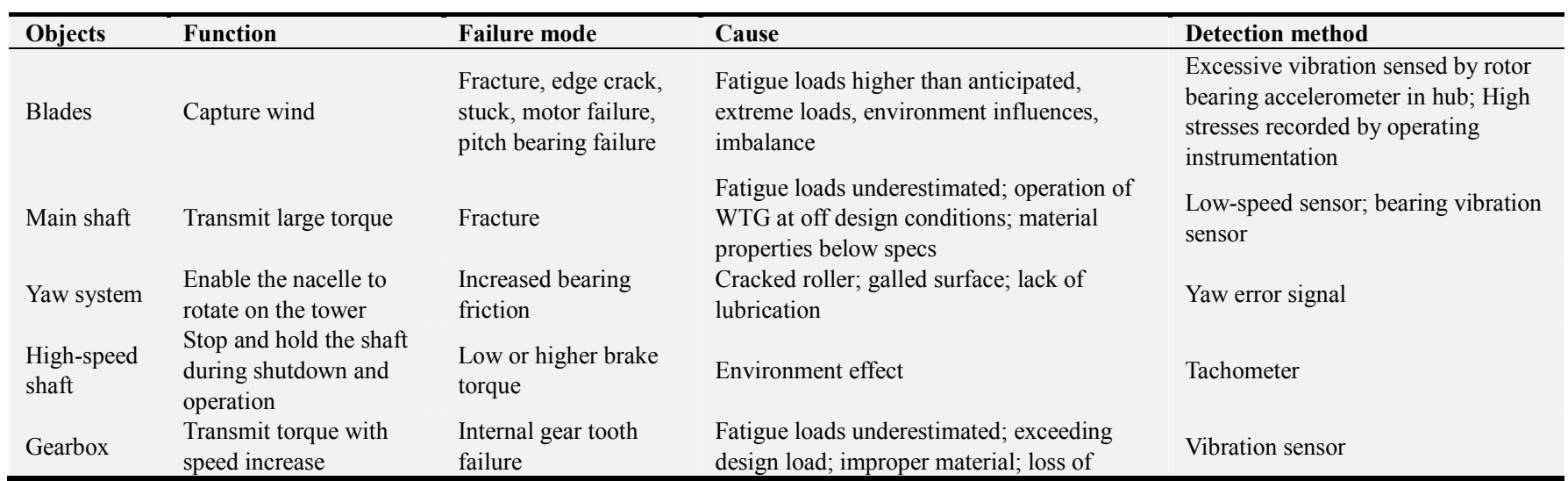




\begin{tabular}{|c|c|c|c|c|}
\hline Objects & Function & Failure mode & Cause & Detection method \\
\hline & & & lubricating oil & \\
\hline $\begin{array}{l}\text { Hub } \\
\text { assembly }\end{array}$ & $\begin{array}{l}\text { Transmit torque from } \\
\text { blades }\end{array}$ & $\begin{array}{l}\text { Structure failure; bolt } \\
\text { failure }\end{array}$ & $\begin{array}{l}\text { Excessing design loads; excessive preload; } \\
\text { stress corrosion }\end{array}$ & $\begin{array}{l}\text { Rotor bearing accelerometer; } \\
\text { periodic inspection for loose or } \\
\text { missing bolts }\end{array}$ \\
\hline Oil seals & $\begin{array}{l}\text { Retain oil in main } \\
\text { bearing housing; } \\
\text { exclude foreign matter }\end{array}$ & Cut or wear in lip & Installation damage; wear & Low oil switch \\
\hline Filters & $\begin{array}{l}\text { To extract and hold all } \\
\text { particulate contaminants } \\
\text { from hydraulic fluid }\end{array}$ & Case leakage & Damage to case or seals & Low oil; level switch \\
\hline Generator & Generate electric power & $\begin{array}{l}\text { Overheat; fault; } \\
\text { jammed bearing; } \\
\text { bearing seizure; } \\
\text { over-speed; }\end{array}$ & $\begin{array}{l}\text { Overload; no excitation; environmental } \\
\text { effects; misalignment; fatigue; mechanical } \\
\text { failure; loss of drivetrain control }\end{array}$ & $\begin{array}{l}\text { Protective relays; over-speed } \\
\text { detection; testing }\end{array}$ \\
\hline Lubrication & $\begin{array}{l}\text { Lubricate gearbox and } \\
\text { rotor bearing }\end{array}$ & $\begin{array}{l}\text { Loss of oil; } \\
\text { overheating; oil under } \\
\text { temperature }\end{array}$ & $\begin{array}{l}\text { Pump failure; Leakage; Diverting valve } \\
\text { failure; Ambient temperature above or below } \\
\text { design conditions; Excessive friction losses; } \\
\text { Diverting valve failure; }\end{array}$ & $\begin{array}{l}\text { Oil flow switch; oil temperature } \\
\text { sensor; air temperature; }\end{array}$ \\
\hline
\end{tabular}

\subsection{Gearbox Failure Modes}

Whatever key components fail in the gearbox, it may result in high cost of maintenance, high production loss, and longer time to repair, especially for offshore wind turbines. The regular failure modes of gearbox are bearing failures, gear fatigue, wear, fracture, insufficient lubrication, etc. Figure 5 shows three common failure modes of gearbox, in which fatigue failures are the most common. The bolts connecting the front box, ring and middle box sometimes fail, because of the strong and unbalanced axial forces acting on the bolts. The bolts failure is shown in Figure 6. The result of Figure 5 shows that the section is smooth, so the failure is caused by fatigue fracture. However, the experiments show that a relief notch, a proper taper of thread and a thread root radius can increase its carrying capacity and reliability.
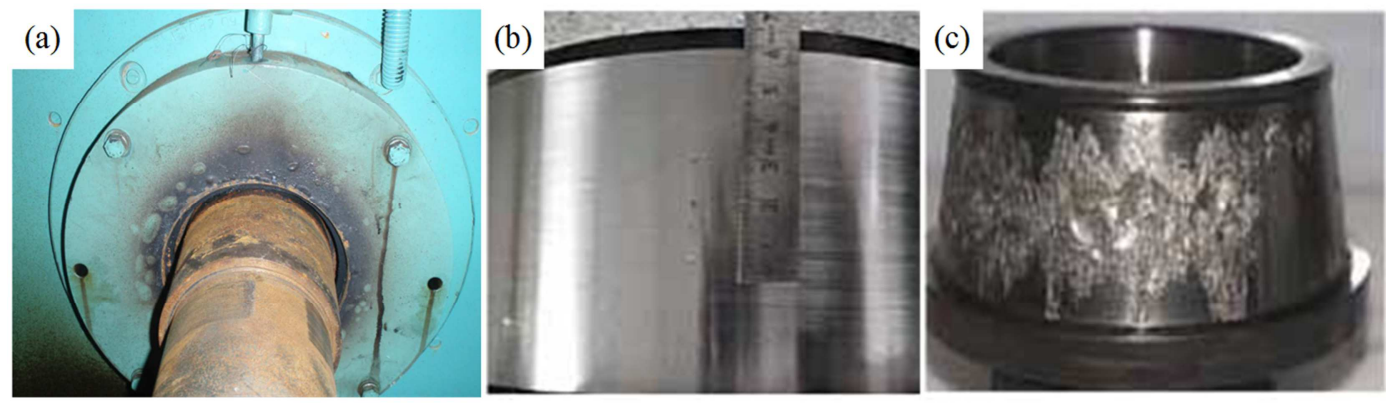

Figure 5. Bearings failure: a) bearing in gearbox; b), c) failure appearance of bearing.
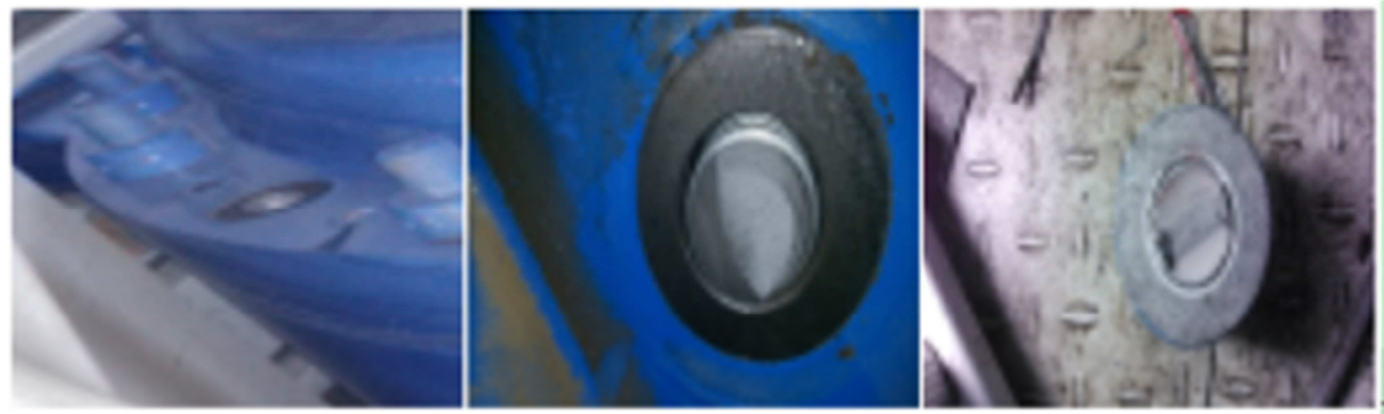

Figure 6. Bolt faults of wind turbine gearbox.

\subsection{Generator Failure Modes}

The generator is one of the most key components with high failure rates since it connects to the high-speed shaft of the wind turbine gearbox with time-varying mechanical torques. Four failure root causes are: design issues, operations issues, maintenance practices and environmental conditions. The failure rates of wind turbine generators have a close relationship to their power rating, working environment, etc. Figure 7 shows failure rates of sub-assemblies of onshore and offshore wind turbine systems. Different failure causes may lead to different generator failure modes, including design issues, operation issues, maintenance and external environment, which is shown in table 3 . Figure 8 shows three common failure modes of the generator where the bearing failure is the most common. 
Table 3. Failure modes of the generator.

\begin{tabular}{ll}
\hline Items & Failure modes \\
\hline Design issues & 1) Electrical insulation inadequate; 2) Loose components (wedges, banding); 3) Crimped lead connections; 4) Transient shaft \\
Operations issues & voltages; 5) Rotor lead failures; 6) Complex structure \\
Maintenance practices & 1) Improper installation; 2) Voltage irregularities; 3) Improper grounding; 4) Over-speed conditions; 5) Transient damage \\
Environmental condition & 1) Winoring alignment; 2) Cooling system failures leading to heat related failure; 3) Bearing failure; 4) Rotor lead failures \\
\hline
\end{tabular}

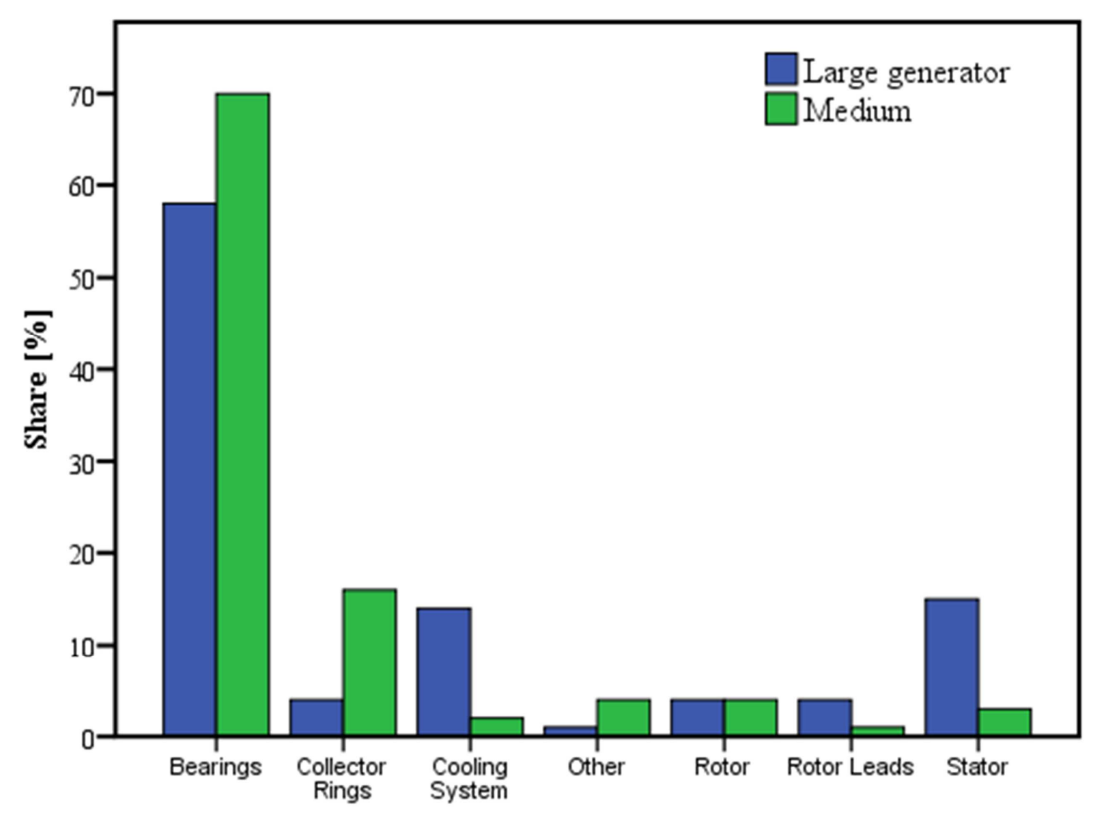

Figure 7. Failure rates of sub-assemblies of onshore and offshore.

\subsection{Rotor Blades Failure Modes}

The rotor blades of wind turbine are driven by the wind energy and transform wind energy to mechanical energy. Because blades often suffer alternating stress and complex environments, they have high failure rates, with the main failure modes being fatigue, fracture, crack, wear, freezing and sensor failure. Figure 9 shows failure modes of the blades. Due to the high location of rotor blades, they are difficult to repair and maintain which leads to high cost. Hence, in order to produce high reliability blades, it is important and meaningful to study the relationship among failure modes, reliability and internal/external loads.

\section{Wind Turbine Reliability Analysis}

The reliability definition is the probability that sub-assembly will meet its required function under a stated condition for a specified period of time. For an unrepairable system, the rating scale is reliability; for a repairable system, the rating scale is availability. Wind turbines consist of both unrepairable systems and repairable systems like gears, bearings, bolts and electronic components. So both reliability and availability should be considered to assess the wind turbines. Figure 10 shows failure rates of different sub-assemblies and its downtime after failure. The results of Figure 10 show that the lower the sub-assembly's reliability is, the longer the downtime of the corresponding sub-assembly is.
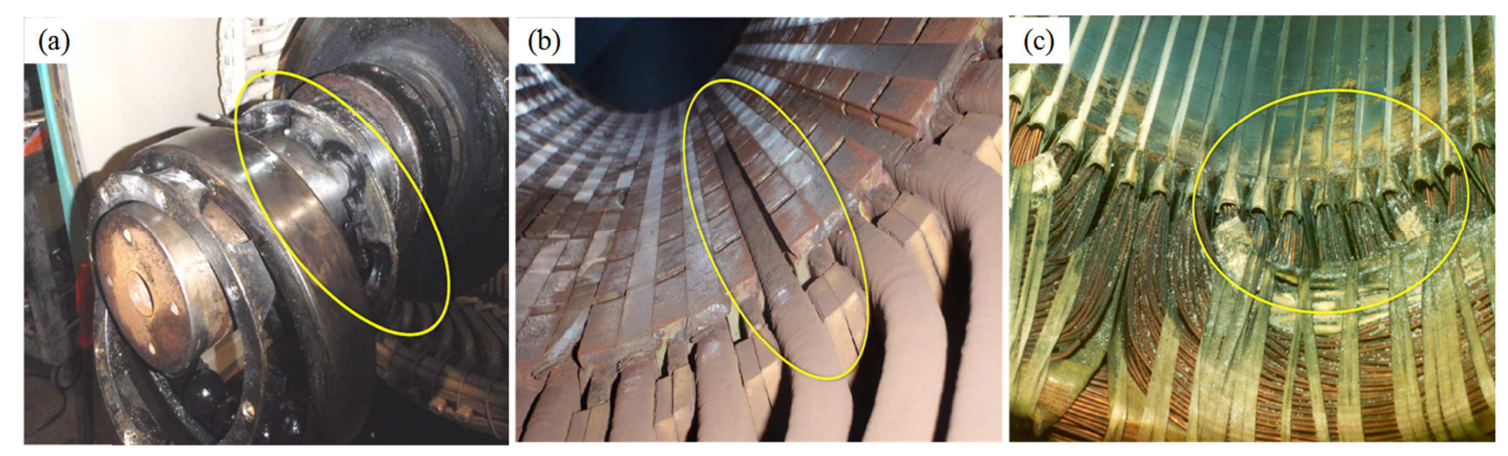

Figure 8. Generator failure: (a) bearing, (b) magnetic wedge loss, (c) contamination. 


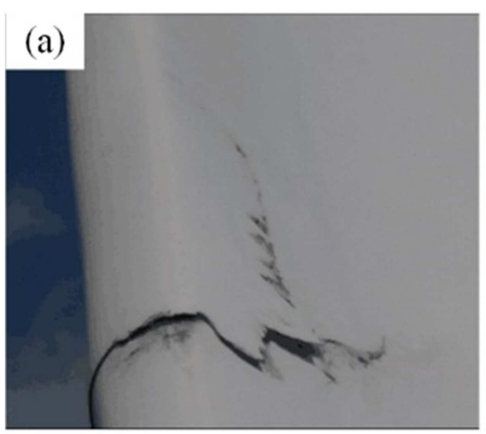

(a) Trailing edge crack (b)

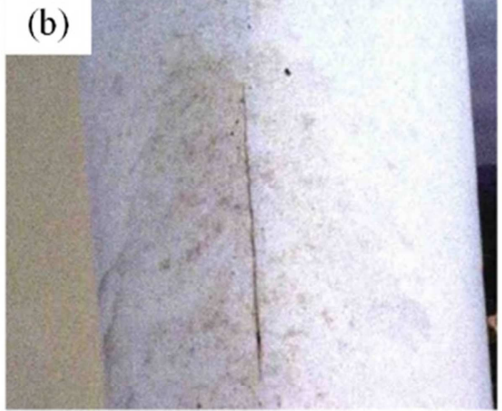

(b) leading edge failure

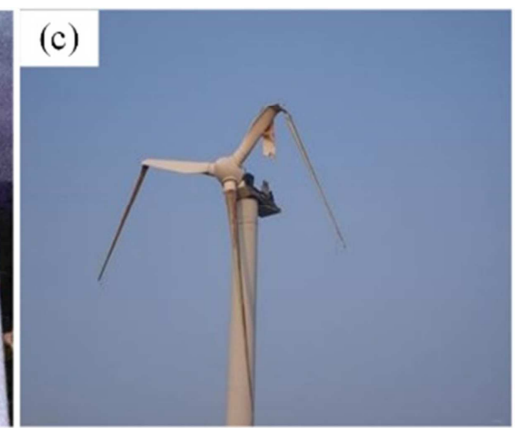

(c) blade fracture

Figure 9. Failure modes of the blades.

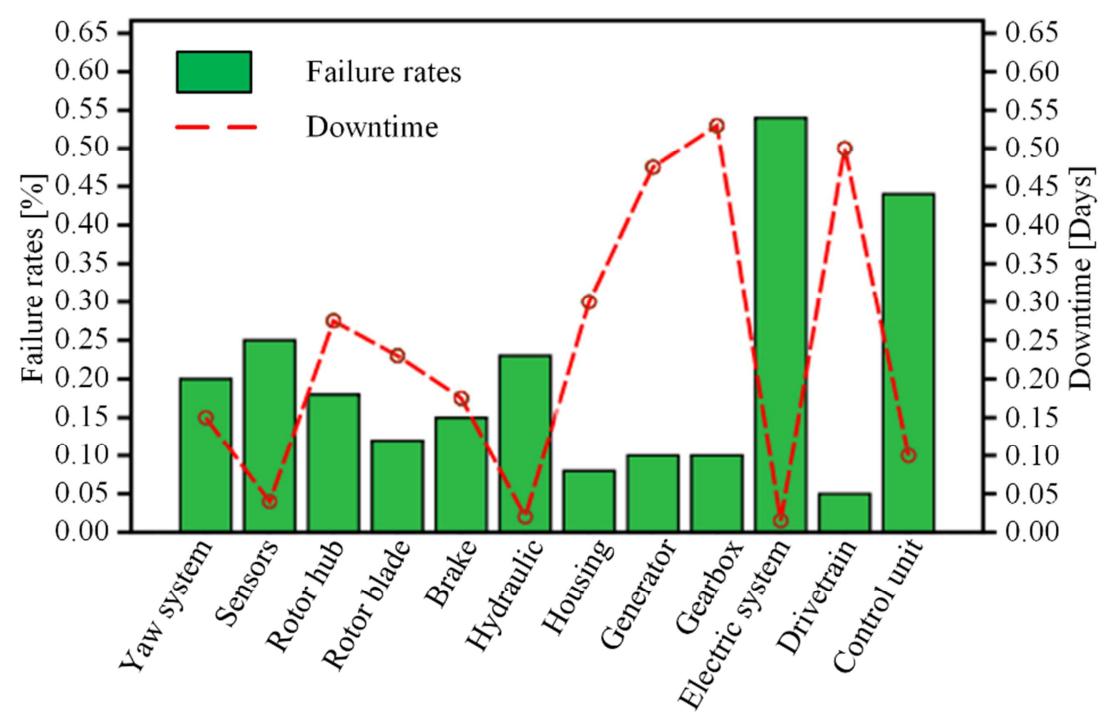

Figure 10. Failure rates and downtime for different sub-assemblies.

The reliability of wind turbine system is becoming more and more important with the continued growth and expansion of markets for wind turbine technology. In addition, the wind turbines with reduced repair and maintenance (R\&M) requirements and higher reliability are needed emergently. However, wind turbines produced by different companies have different reliability. There is no unified evaluation criterion. The current reliability analysis methods mainly focus on gear transmission systems of wind turbines and ignore the influences of other systems. The effects of the reliability model are limited if the system is simplified and seen as a series or parallel connection. Due to high costs of repair and maintenance, it is essential to study health management systems of wind turbines and develop maintenance strategies in order to improve reliability and reduce unexpected repair and maintenance. High reliability systems can be achieved from three aspects, as shown in
Figure 11.

\subsection{Reliability Analysis Methods}

There are two kinds of reliability analysis methods: Statistical method based on database and Stress-strength interference theory based on loads.

(1) Statistical method based on database

The failure rates of wind turbines are time-varying during its lifetime, but the failure rates of repairable systems follow bathtub curve. With a service life of around 20 years, wind turbine failure rates are assumed to follow the famous bathtub curve, as shown in Figure 12. Weibull distribution, Gamma distribution and lognormal distribution are three commonly used methods in wind turbine reliability analysis. A method with mixtures of Weibull distribution with increasing hazard rates is written as follows:

$$
F(t)=\lambda\left[1-\exp \left(-\left(\frac{t-t_{0}}{\eta_{1}}\right)^{\beta_{1}}\right)\right]+(1-\lambda)\left[1-\exp \left(-\left(\frac{t-t_{0}}{\eta_{2}}\right)^{\beta_{2}}\right)\right]
$$

Where $\mathrm{t}$ is time, $t>0, \beta_{1} \cdot \beta_{2}>1, \beta_{1} \cdot \beta_{2}$ are shape parameters, $\beta_{1}, \beta_{2}$ are scale parameters and $\lambda$ is the mixing parameter, $t_{0}=0, \eta_{1}=10, \eta_{2}=100, \beta_{1}=5, \beta_{2}=5$. 


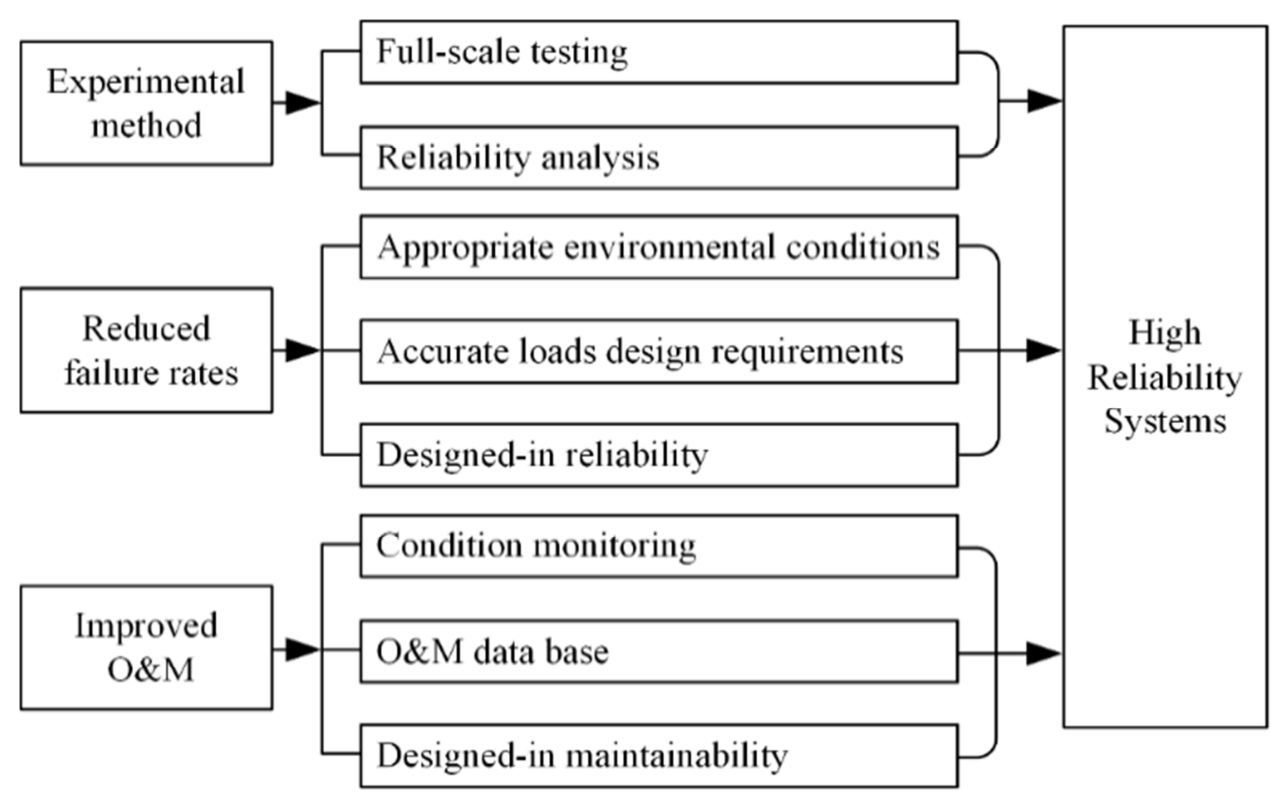

Figure 11. The requirements for developing high-reliability systems.

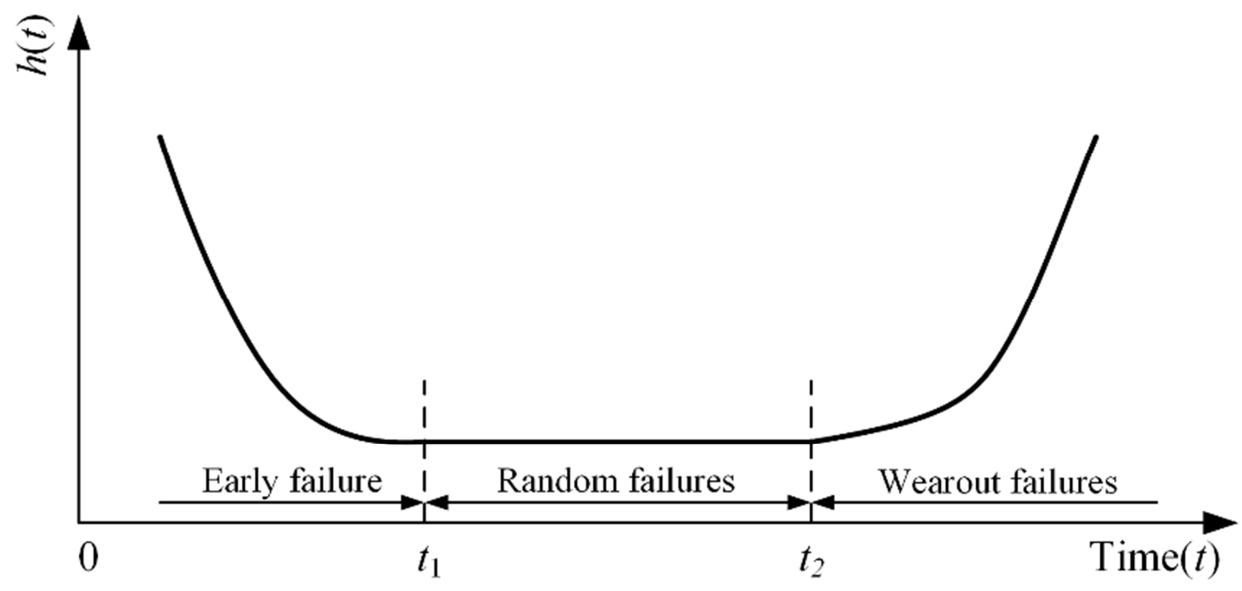

Figure 12. Bathtub curve of failure rates for repairable system.

Figure 13 is the fault probability density function. The results of Figure 13 show that there are two peaks which represent early failures and wear out failures respectively, and the failure rates are obvious higher at these two peaks. When the weighting factor equals $0.1,0.2$, and 0.3 , the differences just happen at the peaks. So a proper weighting factor should be selected to meet the failure rate changes of wind turbines in different working environments. Figure 14 shows the change of failure rates over time. The results of Figure 14 show that a wind turbine is at running-in stage where its wear is large, and the failure rates are fluctuating, and then stable. The failure rates of the wind turbines will become higher and higher at the wear-out stage. Failure rate function curves with different weighting factors just show a difference at peak values, which has something to do with capacity and conditions. Figure 15 shows the reliability function diagram which has three phases. The reliability in Phase I decreases sharply for the reason that newly installed wind turbines need to adapt to the environment. The reliability in Phase II is stable. There is a sharp decline in Phase III, which represents that the wind turbine has entered into wear-out failures and its failure rates are high. Above all, it can be found that the bathtub curve can simulate the failure rate change among its service life well.

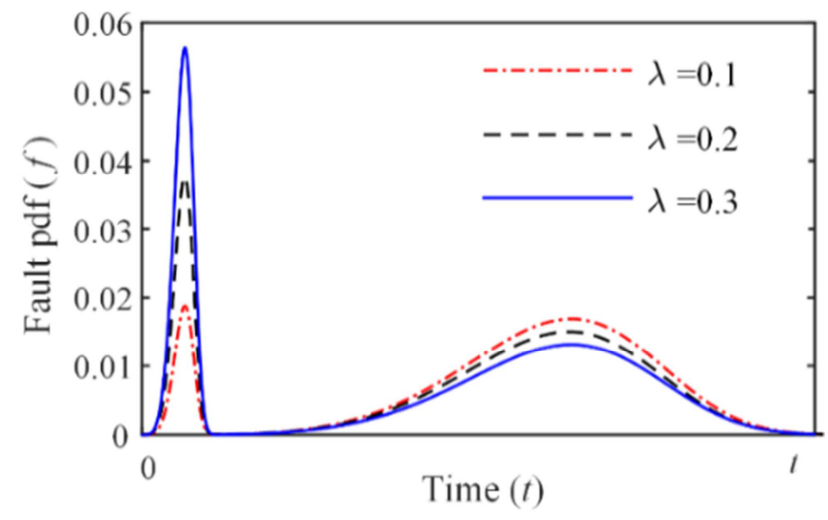

Figure 13. Fault probability density function. 


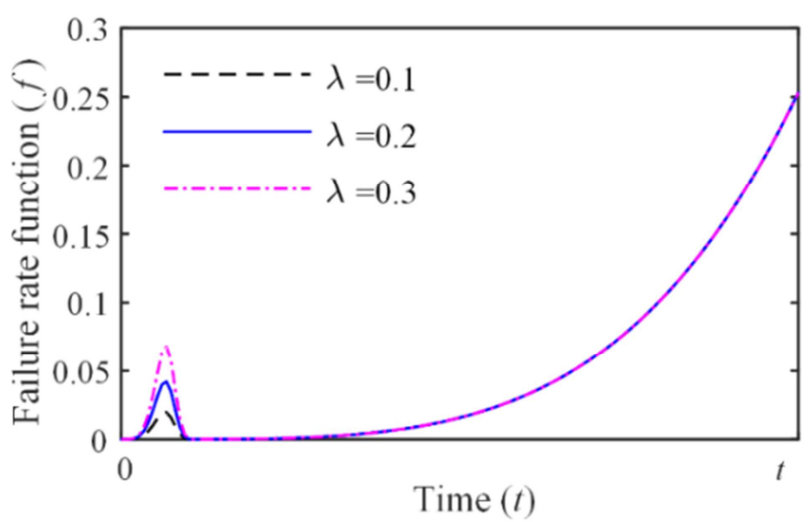

Figure 14. Diagram of failure rate function.

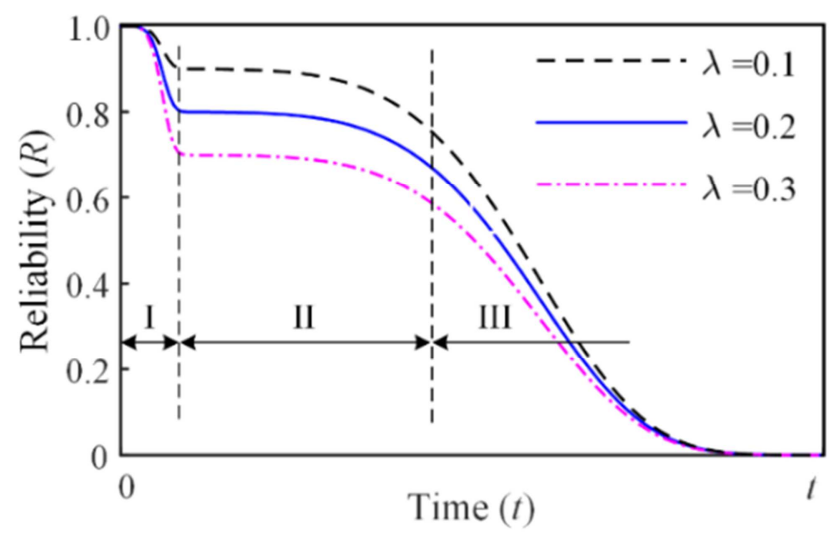

Figure 15. Diagram of the reliability function.

(2) Stress-strength interference theory based on loads

Random loads and fatigue strength of wind turbine subassemblies follow a normal distribution. The probability density function of stress and strength are expressed by the following equations:

$$
\begin{aligned}
& f(S)=\frac{1}{\sqrt{2 \pi} \sigma_{S}} \exp \left(-\frac{1}{2}\left(\frac{S-u_{S}}{\sigma_{s}}\right)^{2}\right) \\
& g(\delta)=\frac{1}{\sqrt{2 \pi} \sigma_{\delta}} \exp \left(-\frac{1}{2}\left(\frac{\delta-u_{\delta}}{\sigma_{\delta}}\right)^{2}\right)
\end{aligned}
$$

Where

$S, \delta$ are stress and strength random variables respectively.

$\sigma_{s}, \sigma_{\delta}$ are the standard deviation of stress random variable and strength random variable respectively.

$u_{s}, u_{\delta}$ are the expectation of stress random variable and strength random variable respectively.

Figure 16 is a common practice to represent stress-strength interference. The figure shows the probability density function of stress and strength and their interference (overlap) over time. The interference is failure probability. The larger the area of interference, the higher the failure probability. Moreover, the interference area will become larger and larger over time in service life. The reliability of the system is:

$$
\text { Reliability }=1-\text { Interference }
$$

A new random variable $z$ can be introduced, which is defined by

$$
z=\delta-S
$$

Then the random variable $\mathrm{z}$ also follows normal distribution, so the reliability of stress-strength interference theory model is:

$$
R=\int_{0}^{\infty} \frac{1}{\sqrt{2 \pi} \sigma_{z}} \exp \left(-\frac{\left(z-u_{z}\right)^{2}}{2 \sigma_{z}^{2}}\right) d z
$$

Where

$\sigma_{z}$ is the standard deviation of $z$.

$u_{z}$ is the expectation of $z$.

The dynamic reliability of gears can be calculated by through the reliability calculation equation with the mean and standard deviation of gear fatigue stress and fatigue strength. Figure 17 is the reliability of high-speed stage gear. The figure shows that the reliability declines heavily before 20,000 hours.

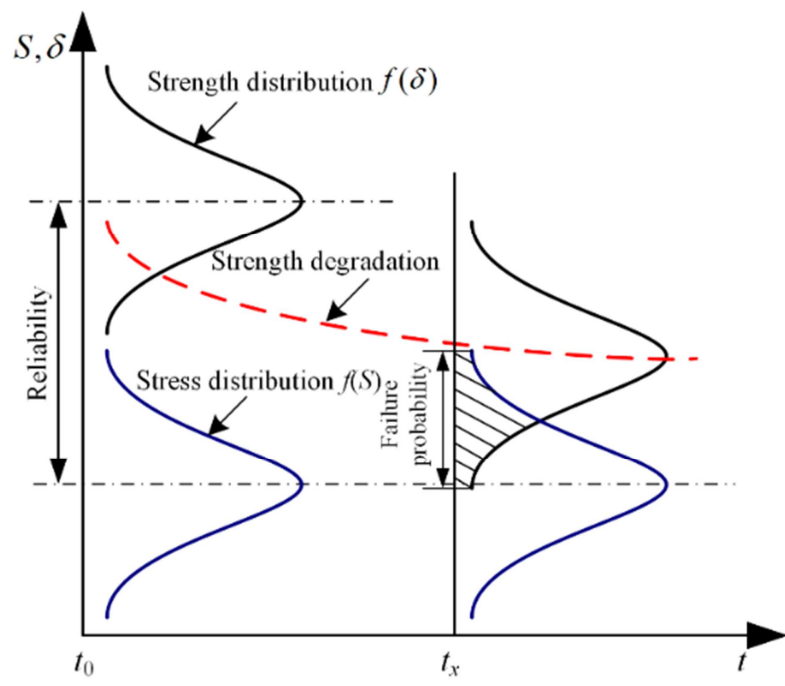

Figure 16. Graphical representation of stress-strength interference.

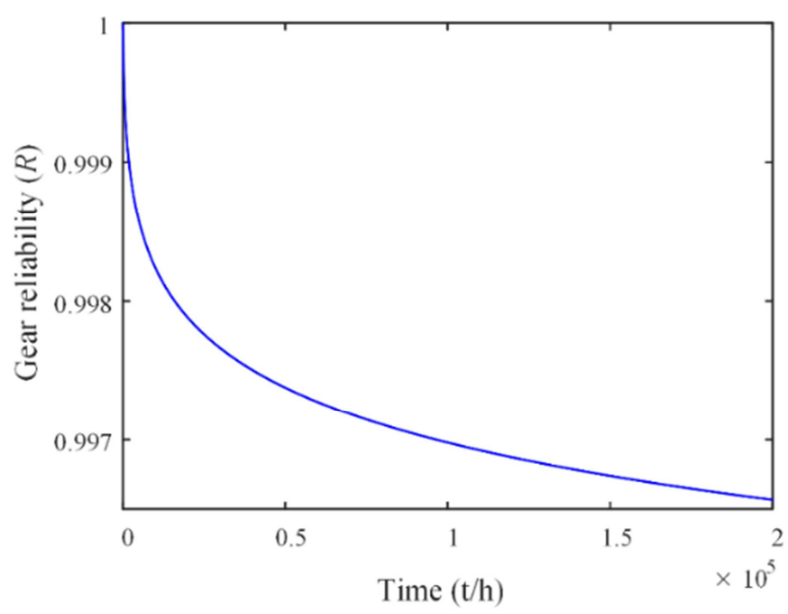

Figure 17. Reliability of high-speed stage gear.

\subsection{Current Gearbox Reliability Analysis}

High-performance gearboxes with large transmission ratios are available, which have been used in many areas. However, wind turbine gearboxes have more challenging and a greater number of technical requirements, like high reliability, safety 
and up to 25 years operating life. Due to its' complex structure and variable conditions, gearboxes have been and still are a source of failure and so have been paid more attention in the industry. Nowadays, the capacity of the multi-stage planetary wind turbines that are installed is up to the megawatt power classes. Hence, it is important to point out that the reliability of wind turbine gearboxes have great influences on the wind turbine.
The current reliability research of the wind turbine gearbox is summarized in table 4 . The methods listed in the table include finite element method (FEM), lumped mass method (LMM), statistical methods based on database, experiment method (EM), simulation with software, etc. Statistical methods based on database are most commonly used.

Table 4. Summary on reliability analysis of gearbox.

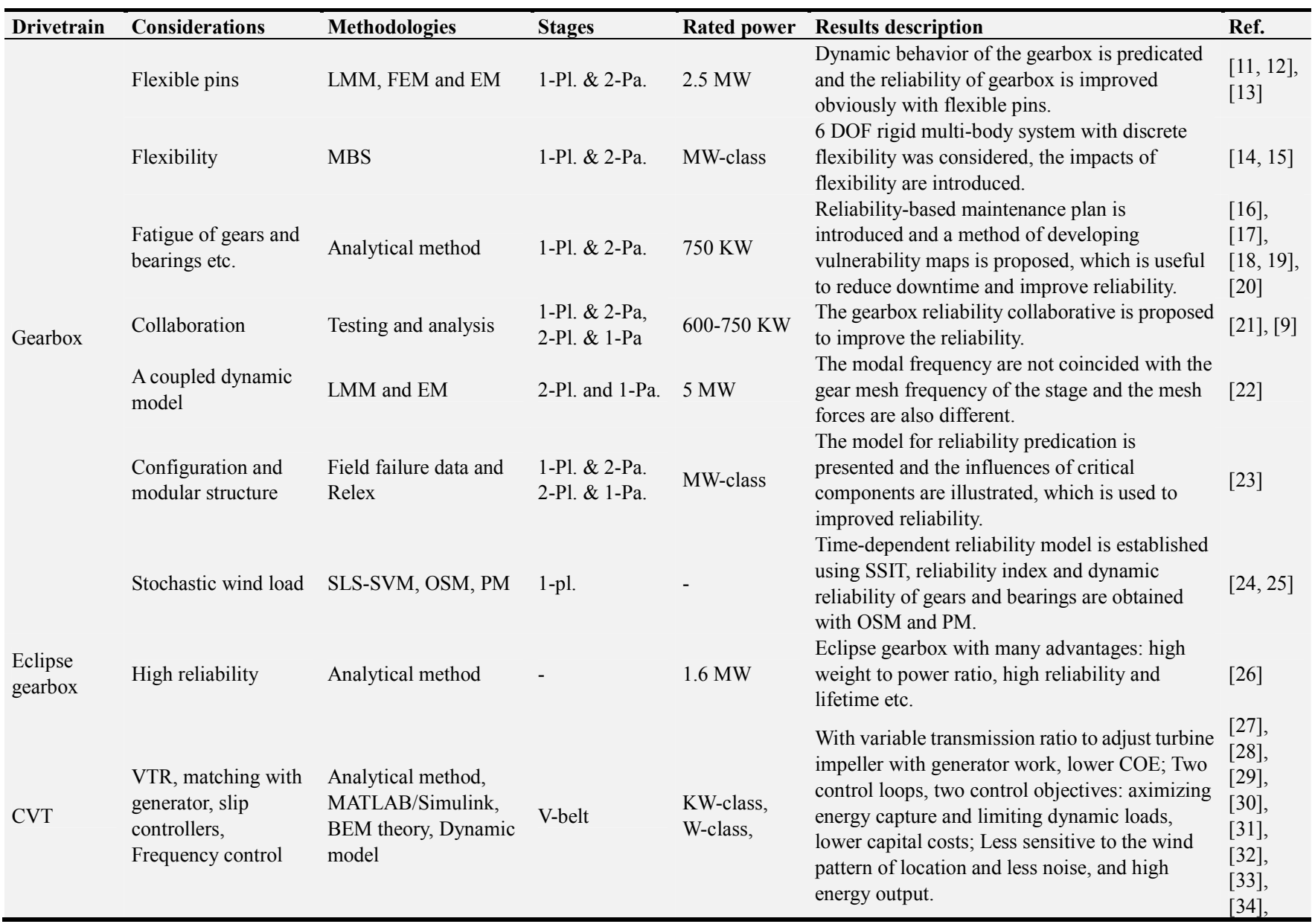

Note: CVT denotes continuously variable transmission, MBS multi-body system approach, VTR variable transmission ratio, BEM blade element momentum, COE cost of energy, Pl. planetary stage, Pa. parallel stage, SLS-SVM sparse least squares support vector machines, OSM order-second moment, PM perturbation method

The researchers in national renewable energy laboratory (NREL) have done much milestone work. Generator and gearbox models have been produced in Matrix Laboratory (MATLAB) and NREL's Fatigue, Aerodynamics, Structures and Turbulence (FAST) [8]. NREL proposed that it is essential to bring all parties involved in the gearbox-design process together to achieve the common goal of improving the reliability and lifetime of gearboxes [9]. The effects of different constant rotor torque and moment conditions and intentional generator misalignment on gearbox motion and high-speed shaft loads are examined [10].

The condition monitoring and fault diagnosis based on condition monitoring system (CMS) and supervisory control and data acquisition (SCADA) are also popular in wind turbine industry. The whole condition monitoring and assessment process within the system boundary include hard platform, condition monitoring and administrators of wind farms. Hard platform for wind farms includes the wind turbines, meteorological stations and monitoring data via CMS and SCADA. Condition monitoring can be divided into remote monitoring system (RMS) and field management information system (FMIS). Where, the FMIS includes data port, field engineer, uninterruptible power system (UPS) and human-machine interaction (HMI); the RMS includes remote replication and a data centre. The boundaries of the condition monitoring and assessment process for the wind turbine gearboxes are shown in Figure 18.

The condition monitoring systems of the CMS and SCADA 
can reflect the real-time running status of the wind turbine gearbox. The framework of the indices and project layers for the assessment of the wind turbine gearbox are established based on the CMS and SCADA. The goal layer can be classified into five project layers, and simultaneously, each project layer consists of the monitoring indices. For example, the goal layer can be divided into main shaft bearing (MSB), planetary stage (PS), low speed stage (LSS), intermediate speed stage (IMS), high speed stage (HSS) and external factors (EF). The monitoring objects mainly consist of the nacelle, main shaft, bearing, cooling system, lubrication system and other related variables.

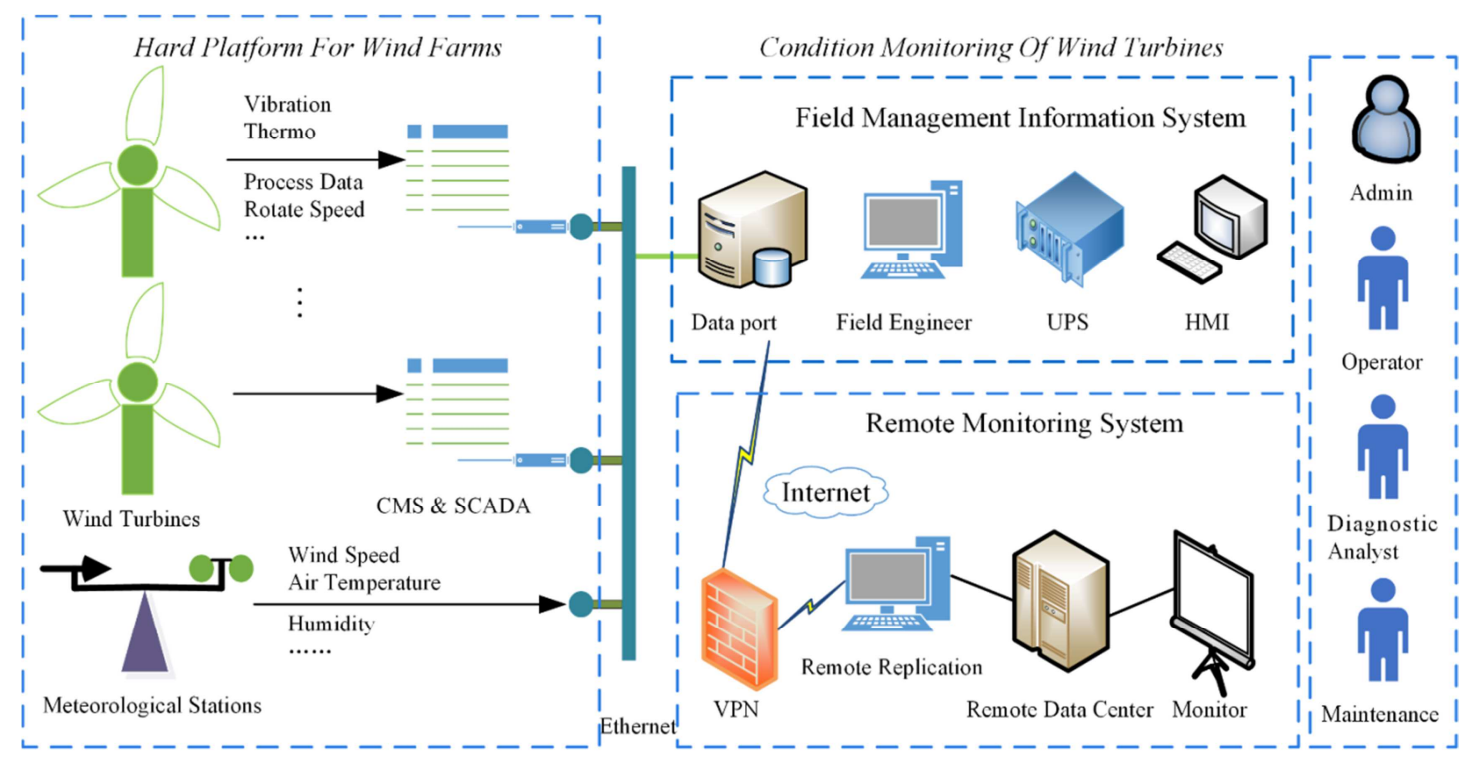

Figure 18. Flowchart of the condition monitoring and assessment process.

\section{Conclusions}

(1) The fatigue failure is the common failure modes of wind turbines. It needs to study the whole wind turbine fatigue life and reliability. With design parameters and the dynamic model, the failure correlation of key components is calculated. Following this, matrixes of loads and contact stresses can be calculated considering the operation environment of wind turbines. Finally, it is possible to produce the fatigue cumulative damage of key components.

(2) Combined loads and fault statistical data, the gradual change mechanism of health status needs to be studied with the function of key components and mechanism characteristics, and to seek the physical representation that is related to the component health status. This is helpful to develop the trend model and thresholds of the physical representation of fault status. Following above, it's possible to assess and pre-estimate the reliability of components and subassemblies.

(3) Considering the influences of the random wind speed and waves, the dynamic model is established including components from blades to the foundation, by which the dynamic reliability of the wind turbine structure and drivetrain is studied. Following this, it's possible to evaluate the dynamic reliability of the whole wind turbine. However, the current reliability research ignored the influences of waves on the foundation and the tower, which would bring big errors to the reliability research. Therefore, it's essential and urgent to develop a set of the reliability engineering model and test method of wind turbines considering the influences of waves and the sea wind.
(4) It's clear that most wind turbines have been installed both SCADA and CMS, but they are independent and can't achieve the mutual support of test results. Due to this reason, it's meaningful to mix two sets of the test data based on SCADA and CMS. Following this, the feature data can be extracted and transferred to the data centre by the Internet. When the feature data reaches the data centre, they can be used to calculate and assess the dynamic reliability of wind turbines through engineering models and hardware and software equipment immediately, which will cut the cost of operation \& maintenance and improve the operating efficiency of wind turbines sharply.

\section{Acknowledgements}

The authors wish to acknowledge the financial support from the Innovation Project of the City of Chongqing (cstc2015zdcy - ztzx70012, cstc2015zdcy - ztzx70010) and Chongqing Graduate Research and Innovation Project (CYB16024).

\section{References}

[1] e. a. Jesse Broehl, "Executive Summary: World Wind Energy Market Update 2017," A BTM NAVIGANT WIND REPORT, 2017.

[2] G. W. E. Council, "Global wind energy outlook 2016," GWEC GLOBAL WIND ENERGY COUNCIL, vol. October, 2016.

[3] G. W. E. Council, "Global Wind Report: Annual Market Update 2016," Global Wind Energy Council, 2016. 
[4] J. M. P. Pérez, F. P. G. Márquez, A. Tobias, and M. Papaelias, "Wind turbine reliability analysis," Renewable and Sustainable Energy Reviews, vol. 23, pp. 463-472, 2013.

[5] "Wind in numbers," Global Wind Energy council, 2014.

[6] IEC61400-1, "Wind turbines-Part 1: Design requirement," WWEA, p. 8, 2014.

[7] F. Dinmohammadi and M. Shafiee, "A fuzzy-FMEA risk assessment approach for offshore wind turbines," IJPHM Special Issue on Wind Turbine PHM (Color), p. 59, 2013.

[8] M. Singh, E. Muljadi, J. Jonkman, V. Gevorgian, I. Girsang, and J. Dhupia, "Simulation for Wind Turbine Generators--With FAST and MATLAB-Simulink Modules," National Renewable Energy Laboratory (NREL), Golden, CO. 2014.

[9] F. Oyague, C. Butterfield, and S. Sheng, "Gearbox reliability collaborative analysis round robin," National Renewable Energy Laboratory, Golden, CO, Report No. NREL/CP-500-45325, 2009.

[10] J. Keller, Y. Guo, and L. Sethuraman, "Gearbox Reliability Collaborative Investigation of Gearbox Motion and High-Speed-Shaft Loads," Contract, 2016.

[11] C. Zhu, X. Xu, H. Liu, T. Luo, and H. Zhai, "Research on dynamical characteristics of wind turbine gearboxes with flexible pins," Renewable Energy, vol. 68, pp. 724-732, 2014.

[12] C. Zhu, X. Xu, T. C. Lim, X. Du, and M. Liu, "Effect of flexible pin on the dynamic behaviors of wind turbine planetary gear drives," Proceedings of the Institution of Mechanical Engineers, Part C: Journal of Mechanical Engineering Science, vol. 227, pp. 74-86, 2013.

[13] L. C.-f. ZHOU Shi-hua, WANG Kai-yu, WEN Bang-chun, "Dynamic Model of the Transmission System in Wind Turbine Gearbox," Journal of Northeastern University (Natural Science), vol. 35, pp. 1301-1305, 2014.

[14] J. Helsen, G. Heirman, D. Vandepitte, and W. Desmet, "The influence of flexibility within multibody modeling of multi-megawatt wind turbine gearboxes," in Proceedings of the ISMA International Conference on Noise \& Vibration Engineering, 2008, pp. 2045-2071.

[15] J. Helsen, P. Peeters, K. Vanslambrouck, F. Vanhollebeke, and W. Desmet, "The dynamic behavior induced by different wind turbine gearbox suspension methods assessed by means of the flexible multibody technique," Renewable Energy, vol. 69, pp. 336-346, 2014

[16] A. R. Nejad, Z. Gao, and T. Moan, "Fatigue reliability-based inspection and maintenance planning of gearbox components in wind turbine drivetrains," Energy Procedia, vol. 53, pp. 248-257, 2014.

[17] Y. Xing and T. Moan, "Multi - body modelling and analysis of a planet carrier in a wind turbine gearbox," Wind Energy, vol. 16, pp. 1067-1089, 2013.

[18] A. Heege, Y. Radovcic, and J. Betran, "Fatigue load computation of wind turbine gearboxes by coupled structural, mechanism and aerodynamic analysis," dEWI Magazin, vol. 28, pp. 61-68, 2006.

[19] A. Heege, J. Betran, and Y. Radovcic, "Fatigue load computation of wind turbine gearboxes by coupled finite element, multi - body system and aerodynamic analysis,"
Wind Energy, vol. 10, pp. 395-413, 2007.

[20] S. Márquez-Domínguez and J. D. Sørensen, "Fatigue reliability and calibration of fatigue design factors for offshore wind turbines," Energies, vol. 5, pp. 1816-1834, 2012.

[21] W. Musial, S. Butterfield, and B. McNiff, "Improving wind turbine gearbox reliability," in European Wind Energy Conference, Milan, Italy, 2007, pp. 7-10.

[22] H. Zhai, C. Zhu, C. Song, H. Liu, G. Li, and F. Ma, "Dynamic modeling and analysis for transmission system of high-power wind turbine gearbox," Journal of Mechanical Science and Technology, vol. 29, pp. 4073-4082, 2015.

[23] K. Smolders, H. Long, Y. Feng, and P. Tavner, "Reliability analysis and prediction of wind turbine gearboxes," in European Wind Energy Conference and Exhibition 2010, EWEC 2010, 2010, pp. 2660-2682.

[24] D. Qin, Z. Zhou, J. Yang, and H. Chen, "Time-dependent reliability analysis of gear transmission system of wind turbine under stochastic wind load," Jixie Gongcheng Xuebao (Chinese Journal of Mechanical Engineering), vol. 48, pp. 1-8, 2012.

[25] D. Qin, Z. Xing, and J. Wang, "Optimization design of system parameters of the gear transmission of wind turbine based on dynamics and reliability," Chinese Journal of Mechanical Engineering, vol. 44, pp. 24-31, 2008.

[26] R. Salunkhe, V. Gambhire, and R. Kapare, "Review on Eclipse Gearbox Reliability."

[27] J. STEFANOVIĆ-MARINOVIĆ, M. BANIĆ, and A. MILTENOVIĆ, "Selection of CVT Transmission Construction Design for Usage in Low Power Wind Turbine," Machine Design, Monograph on the Occasion of 49th Anniversary of the Faculty of Technical Sciences, Faculty of Technical Sciences, Novi Sad, pp. 101-104, 2009.

[28] M. Verdonschot, "Modeling and Control of wind turbines using a Continuously Variable Transmission," Master's Thesis, TU Eindhoven, Eindhoven, The Netherlands, 2009.

[29] J. Cotrell, Assessing the Potential of a Mechanical Continuously Variable Transmission for Wind Turbines: National Renewable Energy Laboratory, 2005.

[30] A. H. Rex and K. E. Johnson, "Methods for controlling a wind turbine system with a continuously variable transmission in region 2," Journal of Solar Energy Engineering, vol. 131, p. 031012, 2009.

[31] D. Alkan, "Investigating CVT as a Transmission System Option for Wind Turbines," 2013.

[32] N. Haro, "Active drive train control to improve energy capture of wind turbines," Boise State University, 2007.

[33] L. Mangialardi and G. Mantriota, "Dynamic behaviour of wind power systems equipped with automatically regulated continuously variable transmission," Renewable Energy, vol. 7 , pp. 185-203, 1996.

[34] H. Beyer, H. Brummer, G. Gerdes, and W. Schmidt, "Optimization of hourly mean power output of wind energy converters with variable rotational speed using a dynamic model," in European Community wind energy conference, 1988, pp. 605-610. 